\title{
THEORETICAL SIMULATION OF PARAMETERS OF CLEANING SUGAR BEET HEADS FROM REMNANTS OF LEAVES BY FLEXIBLE BLADE
}

\author{
Volodymyr Bulgakov ${ }^{1}$, Ivan Golovach ${ }^{1}$, Semjons Ivanovs ${ }^{2}$, Yevhen Ihnatiev ${ }^{3}$ \\ ${ }^{1}$ National University of Life and Environmental Sciences of Ukraine; \\ ${ }^{2}$ Latvia University of Agriculture; ${ }^{3}$ Tavria State Agrotechnological University, Ukraine \\ semjons@apollo.lv
}

\begin{abstract}
In our previous works we obtained analytical dependencies characterising the impact interaction that arises when the heads of the root crops are cleaned from the remnants of tops (leaves) by means of a flexible cleaning blade. In order to find a more perfect and complete result, which could be used by the designers of sugar beet harvesting machines, the research in this technological process needs to be continued in the direction of numerical simulation of the dependencies on the PC. In accordance with the compiled programme of numerical calculations in the Mathcad system, numerical calculations were executed of the kinematic and design parameters of a flexible cleaning blade depending on the design parameters of the cleaning blade, the physical and mechanical properties of the sugar beet tops (leaves) and conditions of cleaning without extracting the roots themselves from the soil. On the basis of the results of calculations graphical dependencies were built of the angular velocity $\omega$ of the rotational movement of the flexible cleaning blade upon the indicated parameters of the cleaner, allowing estimation of their optimal value.
\end{abstract}

Keywords: sugar beet, root crop head, blade, rational parameters.

\section{Introduction}

Precleaning of the sugar beet heads from the remnants of tops (leaves) without extracting from the soil is an urgent and sufficiently complicated problem of the harvesting technological process [1-3]. In conformity with the existing agrotechnical requirements, the amount of the green remnants of the tops (leaves) on the root crop heads during their digging out of the soil must not exceed $3 \%$ [4]. Therefore, the technological process of leaf harvesting includes a separate precleaning operation of the root crop heads from the leaves left unremoved after the main, complete cutting without their extraction from the soil. The most common working tools for the execution of this operation are flexible cleaning blades, which, as rule, are installed by means of pivots on the horizontal drive shaft. Theoretical investigations of the impact interaction of the flexible blade, pivotally fixed on the horizontal drive shaft of the cleaner of sugar beet heads without their extraction from the soil, make it possible not only to establish the basic dependencies between the kinematic and the design parameters of a particular technological process but also serve as the basis for further determination of their rational values. The analytical dependencies obtained by us previously [2;5], characterising the impact interaction arising when the sugar beet heads are cleaned from the remnants of tops (leaves) with a flexible cleaning blade, are the ones that provide a possibility to carry out numerical simulation on the PC in the future and achieve the most perfect and complete investigation of this technological process, the results of which will be useful for the designers and constructors of sugar beet harvesting machines.

There are published a sufficiently great number of scientific works [6-10] etc., devoted to the solution of urgent issues of precleaning the sugar beet heads from the remnants of tops (leaves). There are also results obtained of theoretical and experimental studies of the sugar beet head cleaners of various designs. The most thoroughly investigated are the cleaning blades of the root crop head, most widely used in the world. The most detailed and complete is the theory of impact interaction of the flexible cleaning blade and the sugar beet head fixedly located in the soil [11]. However, the analytical dependencies presented there are not solved numerically, which does not give a complete idea about rational parameters of the cleaning blade of the root crop heads. Therefore, in order to carry out successful designing and development of new cleaner designs for cleaning the sugar beet heads from the remnants of tops (leaves) without extracting from the soil, it is necessary to conduct analysis of the obtained analytical dependencies and to perform their numerical simulation, which will provide a foundation for the application of rational kinematic and design parameters of the cleaners of the root crop heads [2].

The aim of the work was to carry out numerical simulation on the PC of the previously obtained analytical dependencies concerning impact interaction of a flexible cleaning blade with the sugar beet 
head without its extraction from the soil, and to determine on this basis rational parameters of a root crop head cleaner equipped with a blade which is pivotally installed on the horizontal drive shaft.

\section{Research methods}

As a result of a previously conducted theoretical investigation [11], a force diagram was worked out of the interaction of a single flexible cleaning blade with the sugar beet head fixedly located in the soil, the upper part of which projects to a certain height above the soil surface and has uncut remnants of leaves on its periphery (Fig. 1). In this connection a flexible cleaning blade $A M$ is studied, which is pivotally suspended on the axis $A$. The pivot $A$ is fixed on the generatrix of the cleaner cylinder with a radius $r$. The design and kinematic parameters of the simplest cleaner are: the end of the blade describes a circle with a radius $\rho$ in rotation with a constant angular velocity $\omega$ in a longitudinalvertical plane; the axis of the horizontal drive shaft (point $O$ ) is moving above the surface of the soil at a height $H$. The axis of rotation $O$ of the simplest cleaner performs forward movement with a constant velocity of forward movement $\bar{V}_{o}$. The force diagram shows the rectangular Cartesian coordinate system $x O z$, in which the horizontal axis $O x$ coincides with the direction of the forward movement of the cleaner, but the axis $O z$ - is directed up. In this case the length of the blade is equal to $2 l$. Point $M$, which belongs at the same time to the flexible cleaning blade $A M$ and the sugar beet head, is the impact point. The physical sense of other applied forces is clear from the force diagram (Fig. 1).

As a result of previously conducted theoretical investigations [9], an expression was obtained for the angular velocity $\omega$ of rotation of a flexible cleaning blade around point $O$, considering the condition that the sugar beet root is not kicked out of the soil during the stripping (crumpling) process of the remaining leaves from the head [11]:

$$
\omega=\frac{Q V_{o} t_{1}^{2}}{2\left[I_{c}+m(r+l)^{2}\right]\left(\varphi_{1}-\omega_{1} t_{1}\right)-Q(r+2 l) t_{1}^{2}}+\omega_{1},
$$

where $Q$ - stripping (crumpling) force of the remnants of leaves, $\mathrm{N}$;

$m$ - mass of the blade, $\mathrm{kg}$;

$V_{o}$ - velocity of the forward movement of the blade together with its axis of rotation, $\mathrm{m} \cdot \mathrm{s}^{-1}$;

$t_{1}$ - contact time of the blade with the root crop head, s;

$I_{c}$ - inertia moment of the blade in relation to the axis through the centre of masses (point

$C$ ) of the blade, parallel to the axis of rotation of the shaft (point $O$ ), $\mathrm{kg} \cdot \mathrm{m}^{2}$;

$\omega_{1}-$ angular velocity of the blade in relation to point $A$ after the impact, $\mathrm{s}^{-1}$;

$2 l$ - length of the blade, $\mathrm{m}$;

$r$ - radius of the blade suspension on the horizontal drive shaft (cylinder) of the cleaner.

In this case the inertia moment $I_{c}$ of the flexible cleaning blade in expression (1) in relation to the axis through the centre of masses of the blade (point $C$ ), parallel to the axis of rotation of the shaft (point $O$ ), depends on the form of the cross-section of the blade itself. Therefore, two analytical expressions were written for the said inertia moments [12]. Thus, for a flexible cleaning blade of a rectangular parallelepiped form with the sides $2 a \times 2 b \times 2 l$ this inertia moment $I_{c}$ will be equal to:

$$
I_{c}=\frac{m}{3}\left(a^{2}+l^{2}\right)
$$

where $2 a$-width of the cleaning blade;

$2 l$ - length of the blade.

If the cleaning blade has the form of a right circular cylinder, then its inertia moment $I_{c}$ will be equal to:

$$
I_{c}=\frac{m}{4}\left(\frac{4 l^{2}}{3}+r_{1}^{2}\right)
$$

where $r_{1}$-radius of the cross-section of the cleaning blade. 


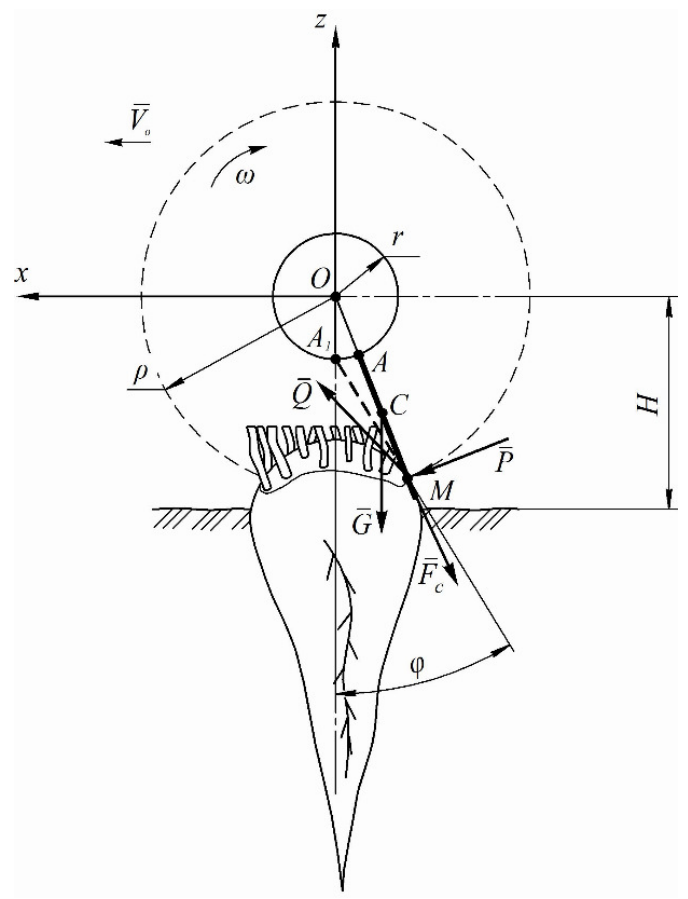

\section{Fig. 1. Force diagram of impact interaction of the flexible cleaning blade} with the sugar beet head

After the programme was compiled in the Mathcad system, numerical calculations of the kinematic and design parameters of the flexible cleaning blade were executed on the PC depending on the design parameters of the cleaning blade, the physical and mechanical properties of the sugar beet tops (leaves) and conditions of cleaning without extracting the roots themselves from the soil. The data of the constant values [5], which were necessary in order to make these calculations are presented in Table 1 .

Table 1

Values of the accepted constants for numerical simulation

\begin{tabular}{|c|c|c|}
\hline Name & $\begin{array}{c}\text { Designation and unit } \\
\text { of measurement }\end{array}$ & Value \\
\hline $\begin{array}{c}\text { Geometrical dimensions of the leaf stalks of } \\
\text { sugar beet }\end{array}$ & $\begin{array}{c}a, \mathrm{~mm} \\
a_{0}, \mathrm{~mm} \\
h, \mathrm{~mm} \\
h_{0}, \mathrm{~mm}\end{array}$ & 2 \\
5 \\
\hline $\begin{array}{c}\text { Number of the remaining leaf stalks on the head } \\
\text { of the sugar beet root }\end{array}$ & $n$, items & 5 \\
\hline $\begin{array}{c}\text { Allowed tangential shear stresses for a leaf stalk } \\
\text { of the sugar beet }\end{array}$ & $\tau, \mathrm{Pa}$ & $0.94-1.14 \cdot 10^{6}$ \\
\hline $\begin{array}{c}\text { Allowed impact force of knocking the sugar } \\
\text { beet root out of the soil }\end{array}$ & $P, \mathrm{~N}$ & $185-432$ \\
\hline
\end{tabular}

\section{Results and discussion}

As a result of the conducted numerical calculations, graphic dependencies have been obtained of the kinematic and design parameters of the technological process of removing the top (leaf) remnants from the sugar beet heads by means of a flexible cleaning blade installed on the horizontal drive shaft. The data are presented in Figs. 2-8.

Fig. 2 presents a graph of the dependence of the angular velocity $\omega$ of rotation of the horizontal drive shaft with a flexible cleaning blade installed on it, depending on the impact time $t_{1}$.

As evident from the presented graphic dependence, with increasing the impact interaction time $t_{1}$ of the flexible cleaning blade with the sugar beet head, changes in the angular velocity $\omega$ of its 
rotational movement have an appearance close to the exponential one. Besides, changing the contact time $t_{1}$ from 0.005 to $0.018 \mathrm{~s}$ ensures the most constant value of the angular velocity $\omega$ of the rotational movement, which should be preferred, i.e. the angular velocity $\omega$ cannot be greater than $20 \mathrm{~s}^{-1}$. Dependencies of the change in the angular velocity $\omega$ of the rotational movement on the length $2 l$ of the blade and its suspension radius $r$, taking into consideration its mass $m$ and length $2 l$, are shown in Fig. 3 and Fig. 4.

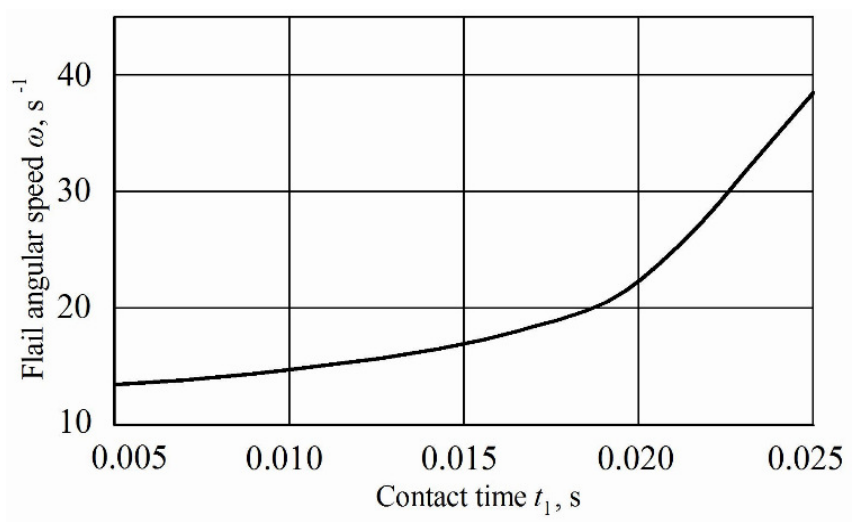

Fig. 2. Dependence of the angular velocity $\omega$ of rotational movement on the impact time $t_{1}$ of the flexible cleaning blade with the sugar beet head

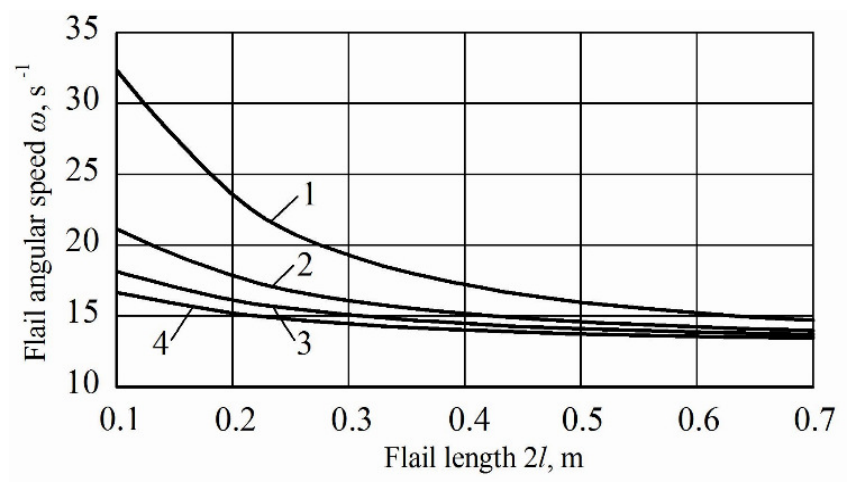

Fig. 3. Dependence of the angular velocity $\omega$ on the length $2 l$ of the cleaning blade at different values of its mass: $1-\mathrm{m}=0.25 \mathrm{~kg} ; 2-\mathrm{m}=0.40 \mathrm{~kg} ; 3-\mathrm{m}=0.55 \mathrm{~kg} ; 4-\mathrm{m}=0.70 \mathrm{~kg}$

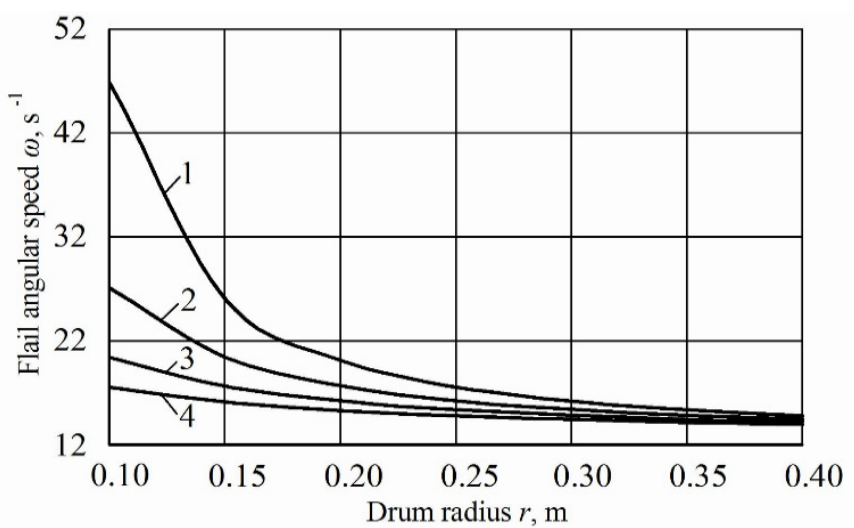

Fig. 4. Dependence of the angular velocity $\omega$ on the suspension radius $r$ of the blade at different lengths of the blade $2 l: 1-2 l=0.1 \mathrm{~m} ; 2-2 l=0.2 \mathrm{~m} ; 3-2 l=0.3 \mathrm{~m} ; 4-2 l=0.4 \mathrm{~m}$

The obtained results witness that the angular velocity $\omega$ of the rotational movement of the flexible cleaning blade is dependent on its length $2 l$, which is close to the exponential. It is also evident that in this case the mass $m$ of the cleaning blade at its minimal value substantially affects the angular velocity $\omega$. If the mass $m$ is increased, it practically has no influence upon this dependency. However, in order to improve the impact of the length $2 l$ of the cleaning blade upon the value of the angular velocity $\omega$, it is necessary to choose the length of the cleaning blade, close to $0.3-0.4 \mathrm{~m}$, which will 
ensure a minimal value of the angular velocity $\omega$ at which high cleaning quality of the sugar beet heads from the remnants of tops (leaves) is achieved without knocking the root crop bodies out of the soil. As regards the dependence of the angular velocity $\omega$ on the radius $r$ of the blade suspension, increasing the value of the particular design parameter of the sugar beet cleaner from the remnants of tops (leaves) without extraction of the heads from the soil will also ensure minimal values of the angular velocity $\omega$ of the rotational movement in case just this length $2 l(2 l=0.3 \ldots 0.4 \mathrm{~m})$ of the flexible cleaning blade is used. Consequently, the horizontal drive cylinder of the sugar beet cleaner from the remnants of tops (leaves) must have a radius not less than $0.25 \ldots 0.3 \mathrm{~m}$ for rational values of the length $2 l$ of the blade.

Dependence of the angular velocity $\omega$ of the rotational movement of the cleaning blade upon the velocity $V_{o}$ of the forward movement of the cleaner, considering the length $2 l$ of the blade itself, presented in Fig. 5, actually has a linear shape.

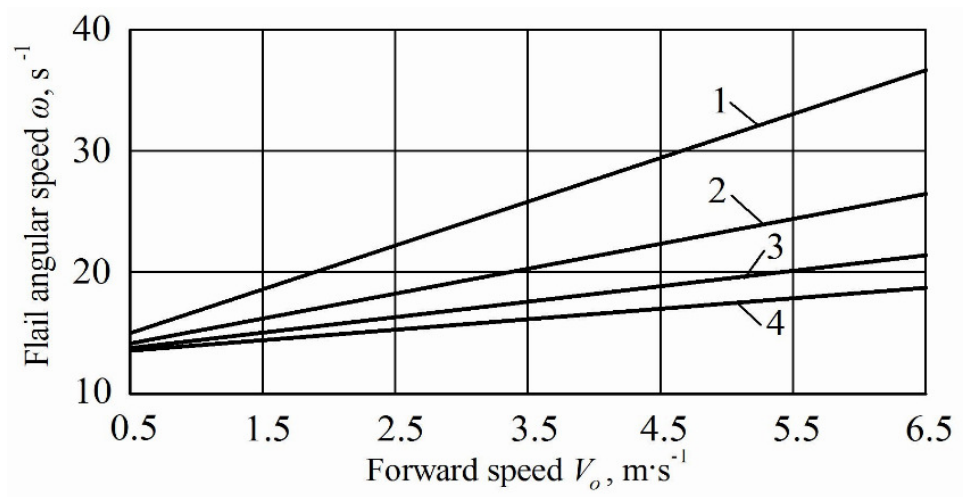

Fig. 5. Dependence of the angular velocity $\omega$ of the rotational movement upon velocity $V_{o}$ of the forward movement at various values of the length of the blade $2 l: 1-2 l=0.1 \mathrm{~m} ; 2-2 l=0.2 \mathrm{~m}$;

$$
3-2 l=0.3 \mathrm{~m} ; 4-2 l=0.4 \mathrm{~m}
$$

The graphs, presented in Fig.5, show that the impact of the length $2 l$ of the blade upon the considered dependency is clearly evident. For instance, with increasing the length $2 l$ of the blade, the values of the angular velocity $\omega$ become considerably lower. Yet, as seen from the graphs, the most rational is the velocity $V_{o}$ of the forward movement of the cleaner, which does not exceed $2.5 \ldots 4.5 \mathrm{~m} \cdot \mathrm{s}^{-1}$. Besides, the length $2 l$ of the cleaning blade should not also be less than $0.3 \ldots 0.4 \mathrm{~m}$.

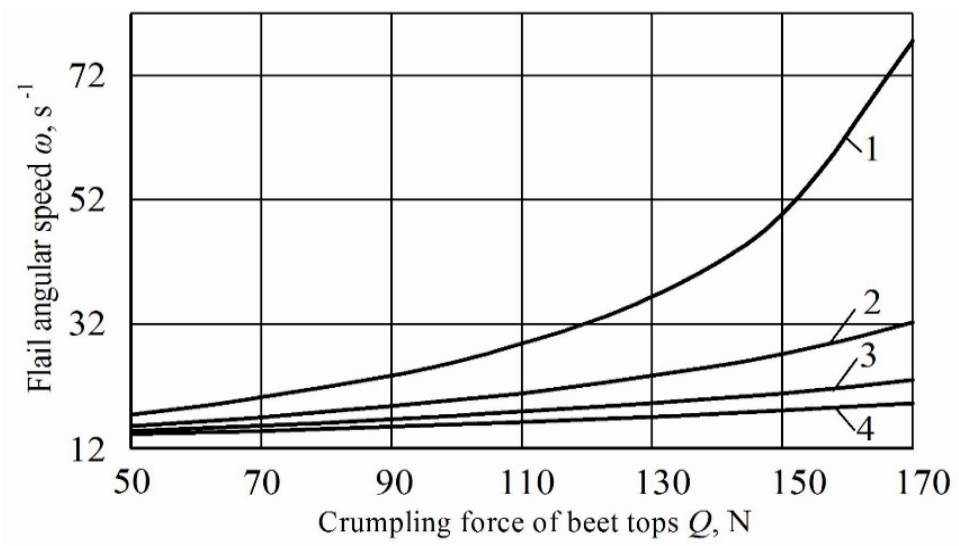

Fig. 6. Dependence of the angular velocity $\omega$ on the stripping (crumpling) force $Q$ at various values of the radius $r: 1-r=0.1 \mathrm{~m} ; 2-r=0.15 \mathrm{~m} ; 3-r=0.2 \mathrm{~m} ; 4-r=0.25 \mathrm{~m}$

As the obtained graphs indicate, the impact of the stripping (crumpling) force $Q$ upon the angular velocity $\omega$ also has a shape, close to the linear dependency. Besides, increased stripping (crumpling) force $Q$ requires adequate increase in the angular velocity $\omega$ of the rotational movement of the cleaning blade. In case radii $r$ of the blade suspension having minimal length $(0.1 \ldots 0.25 \mathrm{~m})$ are used, increase in the angular velocity $\omega$, with the stripping (crumpling) force $Q$ increasing, is more intense than in the case when the value of the radius $r$ is selected close to $0.1 \ldots 0.15 \mathrm{~m}$. However, when the 
stripping (crumpling) force $Q$ is changed in a wide range, preference should be given to an angular velocity $\omega$, equal to $32.0 \mathrm{~s}^{-1}$, but the radius $r$ should not be greater than $0.15 \ldots 0.25 \mathrm{~m}$.

Dependence of the angular velocity $\omega$ of the rotational movement of the cleaning blade on the mass $m$ of the blade itself is shown in Fig.7.

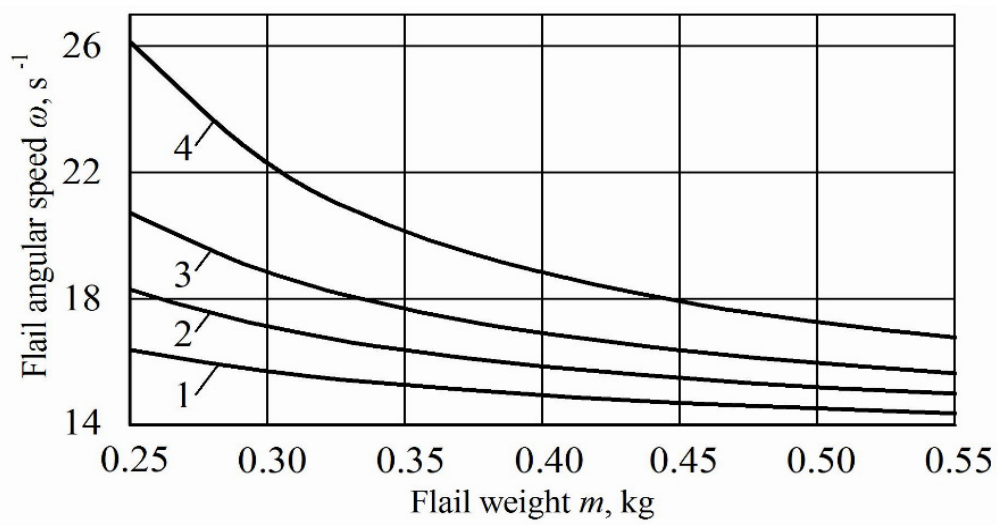

Fig. 7. Dependence of the angular velocity $\omega$ on the mass $\boldsymbol{m}$ of the blade at various values of the stripping (crumpling) force $Q: 1-Q=50 \mathrm{~N} ; 2-Q=70 \mathrm{~N} ; 3-Q=90 \mathrm{~N} ; 4-Q=120 \mathrm{~N}$

As it is obvious from the graphs presented in Fig. 7, the mass $m$ of the flexible cleaning blade should not be less than $0.3 \ldots 0.35 \mathrm{~kg}$, which will ensure high cleaning quality of the sugar beet heads from the tops (leaves) without extracting from the soil at an average value of the stripping (crumpling) force $Q$. Besides, no knocking of the sugar beet roots from the soil will occur.

Dependence of the angular velocity $\omega$ of the rotational movement of the flexible cleaning blade on the length $2 l$ of the blade itself for different forms of its cross section is presented in Fig. 8.

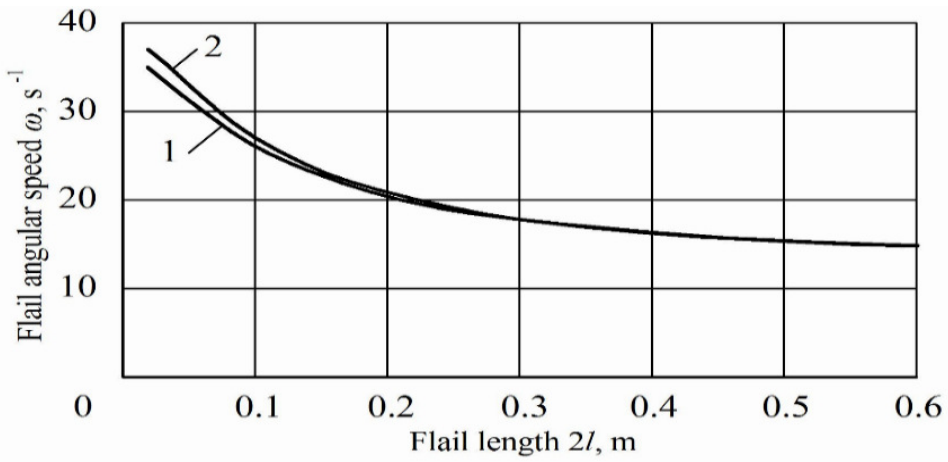

Fig. 8. Dependence of the angular velocity $\omega$ on the length $2 l$ of the blade for different forms of its cross section: 1 - rectangular; 2 - round

The form of the cross section of the flexible cleaning blade leaves substantial impact on the angular velocity $\omega$ of the rotational movement of the blade itself only at small values of its length $2 l$. In case the length $2 l$ of the cleaning blade is used, which was previously defined as rational at other kinematic and design parameters of the cleaner, i.e. greater than $0.15-0.3 \mathrm{~m}$, the form of the cross section of the blade influences only to a minimal degree the said parameters, which ensure high cleaning quality of the sugar beet heads from the top (leaf) remnants without their extraction from the soil. Therefore, when using the length $2 l$ of the flexible cleaning blade, which is greater than $0.3 \mathrm{~m}$, the form of its cross section may be neglected as in this case it is an insignificant parameter.

Consequently, on the basis of the performed numerical simulation on the PC it was established that the most rational kinematic and design parameters of the sugar beet head cleaner from the top (leaf) remnants without extraction and knocking the roots from the soil by means of a flexible cleaning blade, installed on the horizontal drive shaft should be: the length $2 l$ of the flexible cleaning blade must not be less than $0.3 \mathrm{~m}$ but the radius $r$ of the cylinder on which the blade is installed also must not be less than $0.25 \mathrm{~m}$, the velocity $V_{o}$ of the forward movement of the cleaner must not be less than 2.5-3.0 $\mathrm{m} \cdot \mathrm{s}^{-1}$. The result obtained is, in general, consistent with the data of numerous tests of root crop cleaners from the remains of leaves, including those with flexible cleaning blades. Thus, according to 
the data of [13], the forward speed of the sugar beet root cleaners equipped with flexible cleaning blades should not exceed $3.0 \mathrm{~m} \mathrm{~s}^{-1}$, which will ensure that the beet roots are not knocked out of the soil after they are preliminarily cleaned, and high cleaning quality of the heads from the remains of the foliage is achieved. As for the length of the cleaning blade $2 l$, as the results of experimental studies [14] showed, the length of the flexible cleaning blade $2 l$, at which the beet root is not knocked out of the soil, should not exceed $0.32 \mathrm{~m}$. A rational length of the flexible cleaning blade, according to the data of [14], should be equal to $0.23 \mathrm{~m}$. In addition, according to the data given in [2], the value of the angular velocity $\omega$ of the driving shaft with flexible cleaning blades should not exceed $31-38 \mathrm{~s}^{-1}$, which also agrees with the theoretical values of this kinematic parameter obtained by us.

Thus, the experimental studies carried out by other authors fully confirm the theoretical results obtained by us. To ensure high-quality removal of the green and firm remains of the tops from the heads of sugar beet root crops, after the basic complete cutting of its green mass, modern researchers and designers of sugar beet harvesters limit the length of the flexible cleaning blades (taking into account the limitation of size and energy intensity of the process), using more rigid cleaning blades. In this case, short cleaning blades are used of a more rigid material and large geometric dimensions, or reinforcement of the rubber blades with a flexible metal rods is used. Besides, the mass $m$ of the flexible cleaning blade must not be less than $0.3 \ldots 0.35 \mathrm{~kg}$. For the indicated rational parameters of the sugar beet head cleaner without extraction from the soil by means of a flexible cleaning blade, installed on the horizontal drive shaft, the form of the cross section of the blade itself (rectangular or round) has no substantial influence.

Smith L. [5] conducted a study of the effect of increasing the number of cleaning blades and the forward velocity on the cleaning quality of the root crop heads from the remains of foliage with the use of a three-drum defoliator. The results of the tests showed an increase in damage to the heads of the root crops due to the fact that the maximum stripping force of the remains of the tops was not taken into account, which depends on a plurality of kinematic and structural parameters of the cleaning blade and the drum. Therefore, Smith L. noted the need for further careful study of this issue. This is what was done in our study, namely, the determination of the optimal parameters of the cleaning machines with flexible blades, provided that the root crop is not knocked out of the soil and the head is least damaged.

\section{Conclusions}

1. In their final form the obtained solutions of the differential equation of the movement of a flexible cleaning blade along the sugar beet head provided a possibility to obtain new analytical expressions for the determination of the rotation angle and angular velocity of the rotational movement of the cleaning blade installed on the horizontal drive shaft on condition it ensures efficient stripping (crumpling) of the top (leaf) remnants without destructing the ties of the sugar beet roots with the soil, with different values of its geometrical dimensions and forms: a rectangular parallelepiped or a straight round cylinder.

2. The results of the numerical simulation on the PC showed that the rational kinematic and design parameters of the sugar beet head cleaner without extraction from the soil, which ensure a high indicator of the cleaning quality of root crops from the top remnants without knocking the root crops from the soil, are: the velocity $V_{o}$ of the forward movement of the cleaner should not be less than $2.5 \ldots 3.0 \mathrm{~m} \cdot \mathrm{s}^{-1}$, the length $2 l$ of the flexible cleaning blade should not be less than $0.4 \mathrm{~m}$, and the radius $r$ of the cylinder on which the blade is installed also should not be less than $0.3 \mathrm{~m}$. Besides, the mass $m$ of the flexible cleaning blade should not be less than $0.3 \mathrm{~kg}$.

\section{References}

1. Ivančan S., Sito S., Fabijanić G. Factors of the quality of performance of sugar beet combine harvesters. Bodenkultur, No 53(3), 2002. pp.161-166.

2. Погорелый Л. В., Татьянко Н. В. Свеклоуборочные машины (Machines for harvesting sugar beet), Kyiv, 2004, 232 p. (In Ukrainian).

3. Lammers S., Olaf P., Olaf R. Defoliation of sugar beets - assessment of quality and gain in delivered beet mass. Landtechnik, 2010, No.3, pp. 464-467. 
4. Bulgakov V., Ivanovs S., Adamchuk V., Boris A. Mathematical model for determination of losses of sugar bearing-mass when sugar beet tops are removed. Engineering for Rural Development, Proceedings, Vol. 14, 2015, pp. 41-45.

5. Smith L. The effect of defoliator flail configuration, speed and crown removal on sugar beet yield, quality and profitability. Sugar beet Research and Extension Reports, 1991, vol. 22, pp. 222-227.

6. Lilleboe D. Optimizing defoliator \& harvester performance. The sugar beet grower. July 2014, Vol. 53(6), pp. 6-13.

7. Bulgakov V., Orechiwski W., Krasowski E. Experimental investigations of a new working tool for precleaning the sugar beet heads. Current problems of agricultural engineering in an aspect of integration of Poland with European Union: Jubilee international conference XXX years of Agricultural Engineering Faculty at Agricultural University of Lublin, Lublin, 2000. pp. 399-410.

8. Линник А. В. Определение динамических параметров жесткого очистителя при взаимодействии с корнеплодом (Determination of dynamic parameters of a rigid cleaner interacting with a root crop). Вестник Тернопольского национального технического университета. 2014, No.73 (1), pp. 165-171. (In Ukrainian).

9. Булгаков В., Головач И. Дифференциальные уравнения движения гибкой очистительной лопасти по поверхности головки корнеплода (Differential equations of the movement of a flexible cleaning blade along the surface of the root crop head). Механизация и электрификация сельского хозяйства. Glevaha, 2002, Vol.86, pp. 160-165. (In Ukrainian).

10. Булгаков В., Головач И. Теория очистки головок корнеплодов на корню гибкой лопастью (Theory of cleaning the root crop heads without their extraction from the soil by means of a flexible blade). Научный вестник Национального аграрного университета. Kyiv, 2003, Vol. 60, pp. 66-86. (In Ukrainian).

11. Bulgakov V., Ivanovs S., Golovach I., Ruzhylo Z. Theoretical investigations in cleaning sugar beet heads from remnants of leaves by cleaning blade. Engineering for rural development, Proceedings, Vol. 15, 2016, Jelgava, pp. 1090-1097.

12. Dreizler, R.M., Ludde C.S. Theoretical Mechanics. Springer, 2010, 402 p.

13. Погорелый Л., Татьянко Н., Брей В. Свеклоуборочные машины (Machines for harvesting sugar beet). Kyiv, 1983. 168 p. (In Russian).

14. Мартыненко В. Механико-технологические основы повышения эффективности рабочих органов ботвоуборочных машин (Mechanic and technological foundations for increasing the efficiency of the working tools of the haulm removing machines). Ternopol, 2000, $33 \mathrm{p}$. (In Ukrainian). 